\title{
The Effect of Insulin-Loaded Chitosan Particle-Aggregated Scaffolds in Chondrogenic Differentiation
}

\author{
Patrícia B. Malafaya, Ph.D.,, ${ }^{1,2}$ João T. Oliveira, Ph.D., ${ }^{1,2}$ and Rui L. Reis, Ph.D.1,2
}

Osteochondral defect repair requires a tissue engineering approach that aims at mimicking the physiological properties and structure of two different tissues (cartilage and bone) using a scaffold-cell construct. One ideal approach would be to engineer in vitro a hybrid material using a single-cell source. For that purpose, the scaffold should be able to provide the adequate biochemical cues to promote the selective but simultaneous differentiation of both tissues. In this work, attention was paid primarily to the chondrogenic differentiation by focusing on the development of polymeric systems that provide biomolecules release to induce chondrogenic differentiation. For that, different formulations of insulin-loaded chitosan particle-aggregated scaffolds were developed as a potential model system for cartilage and osteochondral tissue engineering applications using insulin as a potent bioactive substance known to induce chondrogenic differentiation. The insulin encapsulation efficiency was shown to be high with values of $70.37 \pm 0.8 \%, 84.26 \pm 1.76 \%$, and $87.23 \pm 1.58 \%$ for loadings of $0.05 \%, 0.5 \%$, and $5 \%$, respectively. The in vitro release profiles were assessed in physiological conditions mimicking the cell culture procedures and quantified by Micro- $\mathrm{BCA}^{\mathrm{TM}}$ protein assay. Different release profiles were obtained that showed to be dependent on the initial insulin-loading percentage. Further, the effect on prechondrogenic ATDC 5 cells was investigated for periods up to 4 weeks by studying the influence of these release systems on cell morphology, DNA and glycosaminoglycan content, histology, and gene expression of collagen types I and II, Sox-9, and aggrecan assessed by real-time polymerase chain reaction. When compared with control conditions (unloaded scaffolds cultured with the standard chondrogenic-inducing medium), insulin-loaded scaffolds upregulated the Sox-9 and aggrecan expression after 4 weeks of culture. From the overall results, it is reasonable to conclude that the developed loaded scaffolds when seeded with ATDC5 can provide biochemical cues for chondrogenic differentiation. Among the tested formulations, the higher insulin-loaded system (5\%) was the most effective in promoting chondrogenic differentiation.

\section{Introduction}

$\mathrm{O}$ STEOCHONDRAL DEFECTS affect both the articular cartilage and the underlying subchondral bone in the joint area and may inflict pain and limited mobility, thereby compromising quality of life. The requirements for a successful regeneration of an osteochondral defect could potentially be met by using a tissue-engineered osteochondral (bone-cartilage) composite of predefined size and shape, generated in vitro using autologous cells. In this sense, various strategies have been reported that result from the use of one or more cell types cultured into single-component or more complex scaffolds in a broad spectrum of compositions and biomechanical properties as recently reviewed. ${ }^{1,2}$ The most attractive approach seems to be the design of a suitable single scaffold that will provide differentiated and adequate conditions for guiding the growth of the two tissues, ful- filling their different biological and functional requirements. Ideally, the scaffold must be able to provide the different and appropriate differentiation cues to promote an adequate development of both cartilage and bone tissues, so that the final hybrid construct can be achieved with the same cell source.

Several works ${ }^{3-7}$ can be found reporting the use of different biomolecules to promote the cell differentiation either as supplements of the culture medium or as loaded in the scaffolds. For instances, Martin et al. ${ }^{7}$ have applied specific regulatory molecules to selectively differentiate bone marrow stromal cells into either cartilaginous or bone-like tissues in conjunction with three-dimensional porous polymeric structures. The work shows that using appropriate chondrogenic (dexamethasone, insulin, and transforming growth factor- $\beta 1$ ) or osteogenic (dexamethasone and $\beta$-glycerophosphate) medium supplements, the generated extracellular matrix (ECM)

\footnotetext{
${ }^{1} 3 B^{\prime}$ 's Research Group, Department of Polymer Engineering, University of Minho, headquarters of the European Institute of Excellence on Tissue Engineering and Regenerative Medicine, Guimarães, Portugal.

${ }^{2}$ PT Government Associated Laboratory, Institute for Biotechnology and Bioengineering (IBB), Guimarães, Portugal.
} 
was cartilaginous (containing collagen type II and sulfated glycosaminoglycans [GAGs]) or bone like (containing osteocalcin, osteonectin, and mineralized foci) after 4 weeks of culture. $^{7}$

Nevertheless, several studies ${ }^{4,8,9}$ address the osteochondral defects regeneration by promoting the repair of articular cartilage that can be further enhanced with controlled release technology approaches. Chondrogenic cells arise from pluripotential mesenchymal stem cells through a series of differentiation pathways, which are being extensively studied. Subsequently, it has been shown that a number of cytokines and transcription factors are involved in chondrocyte maturation and cartilage formation; however, the specific mechanisms regulating these processes remain unclear. ${ }^{10}$ Cell culture is a basic experimental approach used in cellular and molecular biological studies of chondrocytes. ${ }^{10-14}$ The manipulation of the culture environment for chondrocytes presents the most feasible mechanism for optimizing cell behavior and phenotype. Various studies have illustrated the benefits of growth factor integration in establishing and maintaining the phenotype during in vitro cultivation. ${ }^{10,12}$

Among all the growth factors known to be involved in chondrogenesis, insulin-like growth factor (IGF)-1 is considered to be the main anabolic growth factor of normal cartilage, ${ }^{12}$ playing an important role in the growth and differentiation of articular cartilage while also promoting chondrogenic differentiation of mesenchymal cells. ${ }^{15}$ IGF-1 belongs to the IGF family of peptide hormones including relaxin and insulin and has a single polypeptide homologous to proinsulin. ${ }^{10}$ Insulin has not only a great structural similarity to IGF-1 but also a functional similarity, and also elicits marked response in cartilage. ${ }^{13,16}$ It has been demonstrated that in cartilage, the insulin receptor is distinct from the IGF-1 receptors, but that both proteins interact with other's receptors although with significantly lower affinity than those display for their own cognate receptors. ${ }^{13}$ While several studies ${ }^{12,14,17}$ have demonstrated the biological effect of IGF-1 on chondrocytes, the physiological effect of insulin on these cells has not been fully demonstrated. This is due to the potential combined presence of insulin receptors, IGF-1 receptors, and hybrid receptors (which contain both insulin and IGF-1 receptors components). In addition, insulin and IGF-1 can bind each other's receptors and hybrid receptors can bind both growth factors. The ATDC5 cell line, a well-characterized chondrogenic cell line, is routinely induced to differentiate into chondrocytes by exposing the cells to high concentrations of insulin. ${ }^{18}$ This insulin concentration is presumed to exert its effects through the IGF-1 receptors with approximately 100fold lower affinity that IGF-1. ${ }^{18,19}$ Phornphutkul et al. ${ }^{13}$ have reported that insulin is indeed a physiological regulator of chondrogenesis, and that its actions are also mediated by the insulin receptor. In this study, the authors have concluded that insulin is a potent differentiating agent, but not a potent mitogen as IGF-1 for chondrocytes. ${ }^{13}$ In addition, both proliferating and differentiating ATDC5 cells express insulin receptors at the protein level. ${ }^{13}$

It is commonly accepted that investigation of novel systems would benefit from a readily cost model protein such as insulin since the high costs of growth factors often limit the development of new systems. Its incorporation in the scaffolds as controlled release system appears as an attractive strategy for chondrogenic differentiation since it will further allow for selective differentiation required for osteochondral tissue engineering.

Since active biomolecules are normally used as medium supplements ${ }^{7}$ or administrated together at implantation site, ${ }^{20}$ its incorporation in the scaffolds as controlled release systems has become a commonly used strategy. ${ }^{4,21,22}$ This is due to the fact that a single-dose application intraoperatively cannot guarantee a prolonged local protein concentration to achieve permanent stimuli on tissue differentiation, as demonstrated by Gotterbarm et al. ${ }^{20}$ They observed that additional local deposition of liquid growth factors improved the cartilage repair tissue quality at 12 weeks but had not significantly influenced the outcome at 52 weeks. Therefore, release technologies are useful approaches to ensure local release of growth factors over a certain period of time to further improve the quality of the target tissue.

For most tissue engineering applications, a scaffold material is required to not only provide a temporary threedimensional support and framework to form the desired tissues, but also act as a carrier for relevant signal molecules. From the variety of materials that were already investigated, natural materials appear as key candidates due to their properties. $^{22-25}$ Among them, chitosan is being extensively studied, ${ }^{9,26-28}$ namely, for cartilage tissue engineering due to its structural similarity with various GAGs found in articular cartilage, making it an elite scaffolding material for this application. Chitosan structurally resembles GAGs consisting of long chain, unbranched, repeating disaccharide units regarded to play a key role in regulating the expression of the chondrocytic phenotype and in supporting chondrogenesis in vitro as well as in vivo. ${ }^{29}$ The cationic nature of chitosan also allows for electrostatic interactions with anionic GAGs and proteoglycans distributed widely throughout the body and other negatively charged species. ${ }^{30}$ This property is one of the important elements for tissue engineering applications because a number of cytokines/growth factors are known to be modulated by GAGs. ${ }^{27}$ Further, it has been applied as a controlled release system mostly for transforming growth factor- $\beta 1$ in cartilage tissue engineering. ${ }^{29-31}$ Chitosan has adequate properties such as biocompatibility, biodegradability, antibacterial, and wound-healing activity. ${ }^{27}$ It is a promising candidate owing to their porous structure, gelforming properties, ease of chemical modification, and high affinity to in vivo macromolecules.

The present work describes the development and characterization of insulin-loaded chitosan particle-aggregated scaffolds as controlled release systems for chondrogenic differentiation to be further applied in osteochondral tissue engineering. The in vitro assessment of the release profiles of the different formulations was carried out in physiological conditions mimicking the cell culture procedures. Further, the effect on prechondrogenic ATDC5 cells was investigated for different periods studying the influence on cell morphology and proliferation, GAG content, and expression of relevant genes assessed by real-time polymerase chain reaction (PCR).

\section{Materials and Methods}

\section{Scaffold production}

The scaffolds were produced as described elsewhere. ${ }^{26}$ Briefly, chitosan (medium molecular weight and of deacety- 
lation degree $\approx 85 \%$ ) was grinded and dissolved overnight in acetic acid $(1 \% \mathrm{v} / \mathrm{v})$ to obtain a chitosan solution $(2 \% \mathrm{wt})$. After complete dissolution, the chitosan solution was filtered. Unless otherwise stated, all chemicals were bought from (Sigma-Aldrich, Lisbon, Portugal) and used as received. For preparation of insulin-loaded chitosan scaffolds, insulin (from bovine pancreas with molecular weight $\sim 5800 \mathrm{Da}$ ) solutions were prepared in $\mathrm{HCl}(0.1 \mathrm{M})$ for distinct theoretical protein loadings. The protein solution was mixed with the chitosan solution to obtain a homogeneous distribution. Insulin theoretical loadings were $0.05 \%, 0.5 \%$, and $5 \%$ wt relative to chitosan for each formulation. The prepared solutions were extruded through a syringe at a constant rate $(10 \mathrm{~mL} / \mathrm{h})$ to form chitosan droplets into a $\mathrm{NaOH}(1 \mathrm{M})$ precipitation bath where particles with regular diameter were formed. The chitosan particles were quickly washed with distilled water until pH 7. The particles were then placed into moulds and left to dry in an oven at $60^{\circ} \mathrm{C}$ for 3 days. Scaffolds with 3-mmheight and 5-mm-diameter cylindrical shape were obtained.

\section{Insulin-loaded system characterization}

Protein loading and encapsulation efficiency. Protein loading and encapsulation efficiency were calculated by an indirect procedure. After the loaded-particle preparation $(n=3)$ as described previously, particles were separated from the precipitation medium by filtration, and the aqueous phase was sampled for insulin quantification. Nonloaded scaffolds were used as control. The particles were left to dry in a mold at $60^{\circ} \mathrm{C}$, and weighed. The non-loaded-free insulin was determined by Micro-BCA ${ }^{\mathrm{TM}}$ (Micro BCA ${ }^{\mathrm{TM}}$ Protein Assay Kit 23235; Pierce Biotechnology, Rockford, IL). This assay combines the well-known reduction of $\mathrm{Cu}^{2+}$ to $\mathrm{Cu}^{1+}$ by protein in an alkaline medium with the highly sensitive and selective colorimetric detection of the cuprous cation $\left(\mathrm{Cu}^{1+}\right)$ by bicinchoninic acid. The quantification procedure was performed according to the supplier instructions. Briefly, $150 \mu \mathrm{L}$ of each of standards, controls, and samples were placed in triplicate in a 96 -well microplate with $150 \mu \mathrm{L}$ of working reagent supplied in the kit was added to each well. The plate was then mixed thoroughly on a plate shaker for $30 \mathrm{~s}$. The plate was covered and incubated at $37^{\circ} \mathrm{C}$ for $2 \mathrm{~h}$, and cooled to room temperature; the absorbance was measured at $562 \mathrm{~nm}$ on a microplate reader (Synergy HT; BioTek Instruments Limited, Bedfordshire, United Kingdom). The readings were then subtracted of the control (nonloaded scaffolds) and analyzed with respective software (KC4 Microplate Data Analysis Software; BioTek Instruments Limited, Bedfordshire, United Kingdom). A standard curve was then plotted with different insulin concentrations $(0,0.5,1,2.5,5,10,20,40$, and $200 \mu \mathrm{g} / \mathrm{mL}$ ) to determine the insulin concentration of each unknown sample. Samples dilutions were used when necessary. Protein loading was defined as the mass of protein per unit mass of particles as shown in Equation 1, and the encapsulation efficiency is calculated according to Equation 2.

$$
\begin{array}{r}
\text { Protein loading }(\%)=\frac{m_{1}-m_{\mathrm{r}}}{m_{\mathrm{p}}} \times 100 \\
\text { Encapsulation efficiency }(\%)=\frac{m_{1}-m_{\mathrm{r}}}{m_{1}} \times 100
\end{array}
$$

where $m_{1}$ corresponds to the initially loaded weight of protein, $m_{\mathrm{r}}$ is the weight of protein in the precipitation solution, and $m_{\mathrm{p}}$ is the weight of the dry particles prior to in vitro release studies.

In vitro insulin release studies. In vitro release studies were carried out mimicking the cell culture conditions described in the following section. Each insulin-loaded scaffold formulation was placed in a 24-well microplate with $1.5 \mathrm{~mL}$ of phosphate-buffered saline (PBS). The in vitro release studies were carried out in triplicate at physiological conditions ( $\mathrm{pH} 7.4$ and $37^{\circ} \mathrm{C}$ ). Nonloaded scaffolds were used as controls. At predetermined periods and according to the medium replacement in cell culture studies, aliquots $(1 \mathrm{~mL})$ of the supernatant were withdrawn and frozen at $-20^{\circ} \mathrm{C}$ for further protein quantification. The release medium was totally replaced by fresh PBS mimicking cell culture conditions for total medium replacement. The protein quantification was performed using Micro-BCA (Micro BCA ${ }^{\mathrm{TM}}$ Protein Assay Kit 23235; Pierce Biotechnology, Rockford, IL) according to the supplier instructions as described previously.

\section{ATDC5 cells culture in insulin-loaded scaffolds}

Cell culture. Cells used in these experiments were a prechondrogenic murine mesenchymal cell line (ATDC5) purchased from the European Collection of Cell Culture (ECACC; Salisbury, United Kingdom), which differentiates into mature chondrocytes in the presence of insulin. ${ }^{32}$ Cells were plated into tissue culture flasks and incubated at $37^{\circ} \mathrm{C}$ in a humidified atmosphere of $5 \% \mathrm{CO}_{2}$ in air for expansion. ATDC 5 cells were grown as monolayer cultures in a culture medium consisting of 1:1 mixture of Dulbecco's modified Eagle's medium and Ham's F-12 nutrient mixture with $15 \mathrm{mM}$ HEPES, sodium bicarbonate, 10,000 units $/ \mathrm{mL}$ penicillin, $10,000 \mu \mathrm{g} / \mathrm{mL}$ streptomycin, $0.365 \mathrm{~g} / \mathrm{L}$ L-glutamine, and 5\% $(\mathrm{v} / \mathrm{v})$ fetal bovine serum (FBS Heat Inactivated; Biochrom Ltd, Cambridge, United Kingdom) (DMEM/F12). When the adequate cell number was obtained, cells at passage 8 were trypsinized, centrifuged, and resuspended in the cell culture medium. For the control group with nonloaded scaffolds, the standard chondrogenic medium was used that comprised DMEM/F12 supplemented with $10 \mu \mathrm{g} / \mathrm{mL}$ of insulin (DMEM/F12/INS). Cells were seeded at a density of 100,000 cells/scaffold under static conditions using, for this purpose, aliquots of $100 \mu \mathrm{L}$ loaded onto the top of the scaffolds that had been previously placed in 24-well nonadherent tissue culture plates. Two hours after seeding, $1.5 \mathrm{~mL}$ of the respective cell culture medium according to Table 1 was added to each well, and the cell-seeded scaffolds were cultured for 2 and 4 weeks in a humidified atmosphere at $37^{\circ} \mathrm{C}$, containing $5 \% \mathrm{CO}_{2}$. The culture medium was changed every 3-4 days until the end of experiments.

Cell adhesion and morphology. Cell adhesion, morphology, and average distribution were observed by scanning electron microscopy analysis. Briefly, the cell-scaffold constructs were washed in PBS and fixed in 2.5\% glutaraldehyde (in PBS). The constructs were then rinsed in PBS again, and subjected to $15 \mathrm{~min}$ immersion cycles into series of increasing ethanol concentrations $(30 \%, 50 \%, 70 \%, 90 \%$, and $100 \%$ ethanol), each to dehydrate the samples. The samples were finally subjected to critical-point drying by double immersion into hexamethyldisilazane reagent for $15 \mathrm{~min}$ 
Table 1. Scaffold Formulations and the Respective Cell Culture Medium

\begin{tabular}{lll}
\hline Scaffolds & \multicolumn{1}{c}{ Formulation } & Culture medium \\
\hline C & $\begin{array}{l}\text { Nonloaded (control group) } \\
\text { Loaded with 0.05\% (wt/wt) } \\
\text { insulin }\end{array}$ & $\begin{array}{l}\text { DMEM/F12/INS } \\
\text { DMEM/F12 }\end{array}$ \\
0.5 & $\begin{array}{l}\text { Loaded with 0.5\% (wt/wt) } \\
\text { insulin }\end{array}$ & DMEM/F12 \\
5 & $\begin{array}{c}\text { Loaded with 5\% (wt/wt) } \\
\text { insulin }\end{array}$ & DMEM/F12 \\
\hline
\end{tabular}

DMEM, Dulbecco's modified Eagle's medium; F12, Ham's F-12 nutrient mixture with $15 \mathrm{mM}$ HEPES; INS, DMEM/F12 supplemented with $10 \mu \mathrm{g} / \mathrm{mL}$ of insulin.

each, air-dried, and sputter coated with gold (Jeol Ion Sputter JFC-1100, Jeol, Tokyo, Japan) and analyzed with a Leica Cambridge S360 scanning electron microscope (Leica Cambridge Lda, Cambridge, United Kingdom).

DNA quantification. DNA quantification was carried out using PicoGreen ${ }^{\circledR}$ dsDNA Quantitation reagent (Invitrogen SA, Barcelona, Spain) according to the supplier's protocol. Briefly, the cell-scaffold systems were collected at predefined time periods, placed into Eppendorf tubes with $1 \mathrm{~mL}$ ultrapure water, and kept at $37^{\circ} \mathrm{C}$ for $1 \mathrm{~h}$. They were then subjected to two to three cycles of freezing-thawing to assure that the entire DNA would be in solution. Standards of doublestranded DNA were prepared using ultrapure water with the following concentrations: $0,0.2,0.5,1$, and $2 \mu \mathrm{g} / \mathrm{mL}$. Chitosan scaffolds without cells were used as controls. Standards, controls, and samples were placed in 96-well plates in triplicate according to kit instructions where each single well contained $200 \mu \mathrm{L}$ of the total mixture solution. The plates were submitted to a $10 \mathrm{~min}$ incubation cycle in the dark. Emitted fluorescence was read using a microplate reader (Synergy HT; BioTek Instruments Limited, Bedfordshire, United Kingdom), and the data were recorded for analysis with the software (KC4 Microplate Data Analysis Software; BioTek Instruments Limited, Bedfordshire, United Kingdom) (at excitation of $485 / 20 \mathrm{~nm}$ and emission of 528/20 nm).

GAG quantification. Proteoglycan amount was determined by measuring the level of sulfated GAGs using the dimethylmethylene blue metachromatic assay. GAG levels in solution can be quantified using the basic dye, 1,9dimethylmethylene blue, which binds to GAGs generating a metachromatic shift that peaks at $A_{525-530}$ that can be measured spectrophotometrically. Briefly, the constructs $(n=3)$ were immersed in a digestion solution with papain and $\mathrm{N}$-acetyl cysteine and incubated at $60^{\circ} \mathrm{C}$ overnight. After digestion was completed, the tubes were centrifuged at $13,000 \mathrm{rpm}$ for $10 \mathrm{~min}$, and the supernatant was collected. Chondroitin sulfate standard solutions were prepared with different concentrations $(0,2.5,5,10,15,20,25,30,35,40,45$, and $50 \mu \mathrm{g} / \mathrm{mL}$ ) to establish the calibration curve for unknown sample quantification. Chitosan scaffolds without cells were used as controls. Standards, controls, and samples $(20 \mu \mathrm{L})$ were placed in triplicate in a 96-well plate, and then $250 \mu \mathrm{L}$ of 1,9-dimethylmethylene blue solution was added to each well. The optical density was measured at $530 \mathrm{~nm}$ using a micro- plate reader (Synergy HT; BioTek Instruments Limited, Bedfordshire, United Kingdom), and the data were analyzed with software (KC4 Microplate Data Analysis Software, BioTek Instruments Limited, Bedfordshire, United Kingdom).

Histological analysis. Concerning the histological analysis, hematoxylin-eosin (H\&E) staining and toluidine blue staining were performed on $10-\mu \mathrm{m}$-thick sections of cellscaffold constructs $(n=3)$ collected at different periods of culture. The samples were fixated by immersion for $30 \mathrm{~min}$ in glutaraldehyde $2.5 \%(\mathrm{v} / \mathrm{v})$ at $4{ }^{\circ} \mathrm{C}$, and washed in PBS. Histological processing was performed using Technovit $7100^{\circledR}$ (Heraeus Kulzer GmbH, Hanau, Germany) according to the supplier protocol, and sections were sliced using a motorized rotary microtome (Leica RM2155; Leica Biosystems Nussloch $\mathrm{GmbH}$, Nussloch, Germany). H\&E staining was performed using an automatic processor according to in-house methodology (Leica TP1020-1; Leica Biosystems Nussloch GmbH, Nussloch, Germany), and toluidine blue staining was performed as follows. Briefly, sections were hydrated in distilled water and stained in $1 \%$ toluidine blue working solution for 2-3 min. Afterward, they were washed three times in distilled water and quickly dehydrated through 95\% ethanol and $100 \%$ alcohol. Sections were then cleared in Histoclear ${ }^{\circledR}$ (National Diagnostics, Atlanta, GA) and mounted using Microscopy Entellan ${ }^{\circledR}$ (Merck SA, Lisbon, Portugal) for observation.

Evaluation of gene expression by real-time PCR. Samples $(n=2)$ were collected at the defined time periods, quickly frozen in liquid nitrogen, and stored at $-80^{\circ} \mathrm{C}$ until further analysis. RNA was extracted using TRIzol ${ }^{\circledR}$ (Invitrogen SA, Barcelona, Spain) according to the supplier protocol. Briefly, samples of each condition were grinded and mechanically homogenized with a mortar and pestle in TRIzol reagent. Afterward, chloroform was added, and the samples were centrifuged to establish a three-phase composition in the tube. The aqueous phase was collected and put in a new tube where isopropanol was added. The samples were once again centrifuged, the supernatant was discarded, and the pellet was washed with $75 \%$ ethanol. The samples were again centrifuged, let to air-dry, and suspended in ultrapure water for posterior analysis. The amount of isolated RNA and A260/280 ratio was determined using Nanodrop ND1000 Spectrophotometer (NanoDrop products; Thermo Scientific, Wilmington, DE). After these determinations, $1 \mu \mathrm{g}$ of RNA of each sample was reverse transcribed into cDNA using the IScript ${ }^{\mathrm{TM}}$ CDNA synthesis kit (Bio-Rad Laboratories Lda, Lisbon, Portugal) in an MJ Mini ${ }^{\mathrm{TM}}$ Personal Thermal Cycler (Bio-Rad Laboratories Lda, Lisbon, Portugal). Cartilage-related markers were chosen to evaluate the chondrogenic phenotype of the cultured systems. These included collagen type I, collagen type II, Sox-9, and aggrecan, using GAPDH as the housekeeping gene for normalization. The expression of each gene was normalized to the GAPDH value in that sample. All the primer sequences were generated using Primer3 software and acquired from MWG Eurofins MWG Operon (Ebersberg, Germany). More details can be found in Table 2. Real-time PCR was performed using SYBR Green IQ ${ }^{\mathrm{TM}}$ Supermix (Bio-Rad Laboratories Lda, Lisbon, Portugal) to detect amplification variations in an MJ Mini Personal Thermal Cycler (Bio-Rad Laboratories Lda, 
Table 2. Primers Used for Real-Time Polymerase Chain Reaction Evaluation of ATdC5 Gene Expression

\begin{tabular}{llll}
\hline Gene & \multicolumn{1}{c}{ Accession } & \multicolumn{1}{c}{ 5-Primer } & 3-Primer \\
\hline Collagen type I & NM_007742 & GAGCGGAGAGTACTGGATCG & GCTTCTTTTCCTTGGGGTTC \\
Collagen type II & NM_001113515 & GCCAAGACCTGAAACTCTGC & GCCATAGCTGAAGTGGAAGC \\
Sox-9 & NM_011448 & AGCTCACCAGACCCTGAGAA & TCCCAGCAATCGTTACCTTC \\
Aggrecan & NM_007424 & TGGCTTCTGGAGACAGGACT & TTCTGCTGTCTGGGTCTCCT \\
GAPDH & NM_008084 & AACTTTGGCATTGTGGAAGG & ACACATTGGGGGTAGGAACA \\
\hline
\end{tabular}

Lisbon, Portugal) machine. The results were analyzed using MJ Opticon Monitor 3.1 software (Bio-Rad Laboratories Lda, Lisbon, Portugal).

\section{Statistical analysis}

When applicable, the statistical analysis of values obtained with the several characterization techniques was carried out using Student's two-tailed $t$-test with a confidence level of $99.5 \%$. All statistical calculations were performed with Analysis ToolPak software. $p$-Values below 0.05 were considered statistically significant.

\section{Results}

\section{Insulin-loaded chitosan scaffolds}

Protein loading and encapsulation efficiency. The developed insulin-loaded scaffolds were characterized by assessing the encapsulation efficiency and protein loading as shown in Figure 1. Insulin loadings of the scaffolds were $0.0297 \pm 0.0001 \%, 0.3843 \pm 0.0118 \%$, and $3.9911 \pm 0.1159 \%$, as determined by Micro-BCA ${ }^{\mathrm{TM}}$, and correlated well with the intended and designed insulin theoretical loadings of $0.05 \%$, $0.5 \%$, and $5 \%$, respectively. The obtained encapsulation efficiencies were high with values of $70.37 \pm 0.80 \%, 84.26 \pm$ $1.76 \%$, and $87.23 \pm 1.58 \%$ for insulin loadings of $0.05 \%, 0.5 \%$, and $5 \%$, respectively.

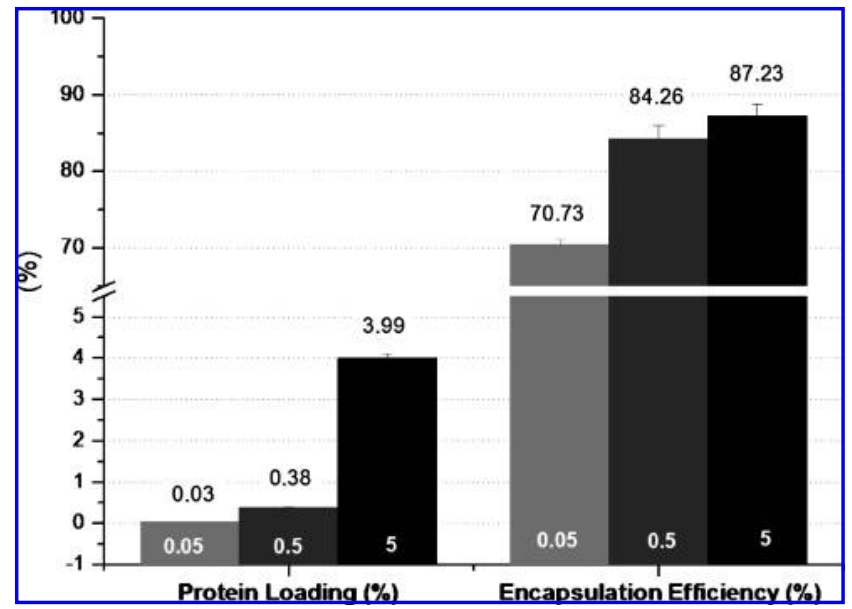

FIG. 1. Protein loading and encapsulation efficiency of chitosan particle-aggregated scaffolds loaded with $0.05 \%$, $0.5 \%$, and $5 \%$ of insulin. Numbers in white represent the theoretical loading value. Data are expressed as mean \pm standard deviation $(n=3)$.
In vitro release studies. The release of insulin from chitosan particle-aggregated scaffolds under physiological conditions was investigated with total medium replacement at the same intervals of cell culture medium replacement ( 3 or 4 days). The assays were performed in this way to mimic exactly the cell culture conditions. The obtained release profiles represented in Figure 2 were characterized by an initial rapid release within the first 4 days with values around $80 \%$ and $60 \%$ of released insulin for $0.05 \%$ and $0.5 \%$ formulations, respectively. This burst effect was less pronounced for the 5\% insulin-loaded scaffolds with a $40 \%$ release in the same initial immersion period. The cumulative release profile shown to be dependent on the initial scaffolds loading, being the release rate slower for higher initial insulin concentrations. For the $0.05 \%$ formulation, the remaining $20 \%$ insulin was almost totally released until day 11 . Further, the release behavior of the $0.5 \%$ appeared similar since more than $60 \%$ of the insulin was released within the first 3 days, and the remaining $40 \%$ insulin was almost released within 18 days. When insulin content increased to $5 \%$, the release rate decreased and only around $85 \%$ insulin was released until the end of the experiment at 28 days, most likely due to its high initial concentration.

The insulin release was also plotted considering the insulin concentrations in the release medium as represented in Figure 3 which are important data, considering the further cell culture studies. The insulin concentrations released to the medium were, as expected, well correlated with the initial loading in the respective order of magnitude. The insulin released to the medium was below $1 \mu \mathrm{g} / \mathrm{mL}$ after day 11 and day 21 for $0.05 \%$ and $0.5 \%$ formulations, respectively. After these time periods and for these formulations, lower amounts of insulin were released and were always below $0.1 \mu \mathrm{g} / \mathrm{mL}$ until the end of the experiments. In contrast, for higher initial insulin loading, protein concentrations were kept always above $80 \mu \mathrm{g} / \mathrm{mL}$ even at the last day of these studies (day 28).

\section{Biological assessment of ATDC5 chondrogenic differentiation by insulin-loaded scaffolds}

Cell morphology. To study the effect of insulin-loaded scaffolds on chondrogenic differentiation, the performance of the scaffolds was investigated in a long-term cell culture with a prechondrogenic cell line (ATDC5) for up to 4 weeks. This study allowed also to assess the bioactivity of incorporated and released insulin from the scaffolds. The results were always compared with standard culture conditions, that is, unloaded scaffolds cultured with the standard chondrogenic medium. Cell morphology was qualitatively evaluated by scanning electron microscopy after 2 and 4 weeks of culture as shown in Figure 4. After 2 weeks of culture, cells had adhered to the chitosan particle-aggregated scaffolds. Chondrocyte cells seeded on insulin-loaded chitosan scaffolds 
FIG. 2. Cumulative insulin release profile for the different formulations of insulin-loaded chitosan scaffolds after immersion in phosphate-buffered saline for up to 28 days ( 4 weeks) with total medium replacement at determined time points mimicking the cell culture conditions. Data are expressed as mean \pm standard deviation $(n=3)$.

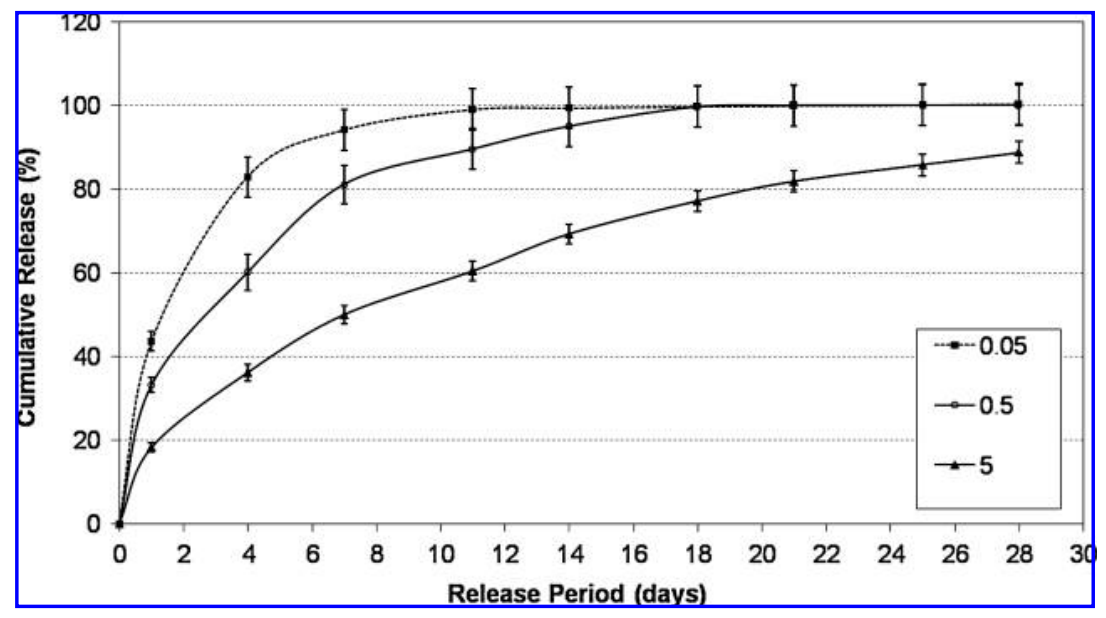

proliferated, possessing a rounded typical chondrocytic morphology, which is an indication of chondrocyte differentiation (Fig. 4C, E, G). Cell condensation and formation of ECM were detected as well, since it is also possible to observe the formation of collagen fibrils. ${ }^{33}$ In contrast, for the control group, cells presented a flattened and spread morphology still showing a fibroblast-like phenotype with some cytoplasmic extensions (Fig. 4A). However, for 4 weeks of culture, in all the studied formulations, the cells maintained a rounded shape morphology and remained aggregated, being this more clear for the $5 \%$ formulation (Fig. 4B, D, F, H). Nevertheless, it was noticeable that, for $0.05 \%$ and $0.5 \%$ insulin loading, the cell distribution over the scaffolds was lower. The formation of ECM including collagen fibrils was also detected being more evident for the control and for the $5 \%$ insulin formulation, where the cells clustering is also visible (Fig. 4B, H).

Cell proliferation. For all the developed formulations, cell proliferation was investigated by DNA quantification after 2 and 4 weeks, and the obtained results are plotted in Figure 5. After 2 weeks of culture, the total amount of DNA in each group was $0.042 \pm 0.029 \mu \mathrm{g} / \mathrm{sample}$ in the control group, $0.026 \pm 0.002 \mu \mathrm{g} / \mathrm{sample}$ in the $0.05 \%$ group, $0.063 \pm 0.002$ $\mu \mathrm{g} /$ sample in the $0.5 \%$ group, and $0.091 \pm 0.008 \mu \mathrm{g} /$ sample in the $5 \%$ group. The amount of DNA presented an increasing trend for higher insulin loading, where the $5 \%$ group is significantly higher than other formulations. This increasing tendency for higher values of insulin loading was maintained after 4 weeks with all DNA values statistically different, except between $0.5 \%$ and $0.05 \%$ formulation. At 4 weeks, the obtained values were $0.533 \pm 0.033 \mu \mathrm{g} /$ sample for the control, $0.029 \pm 0.007 \mu \mathrm{g} /$ sample for $0.05 \%, 0.040 \pm 0.011 \mu \mathrm{g} /$ sample for $0.5 \%$, and $0.084 \pm 0.002 \mu \mathrm{g} /$ sample for the $5 \%$ insulin loading group. For longer time periods, there is a decreasing trend between the same conditions (with the exception of the control group) compared with shorter periods.

GAG quantification. GAGs are important components of proteoglycans and are typically present in the cartilaginous ECM being aggrecan the most relevant in terms of mechanical functionality. GAG content was determined to assess the formation of newly formed ECM and thus, if occur, the differentiation of ATDC5 into chondrocytes in these insulin-
FIG. 3. Insulin concentration in the release medium for chitosan-loaded scaffolds with $0.05 \%, 0.5 \%$, and $5 \%$ of insulin immersed in phosphate-buffered saline for up to 28 days ( 4 weeks) with total medium replacement every 3 or 4 days mimicking the cell culture conditions. Data are expressed as mean \pm standard deviation $(n=3)$.

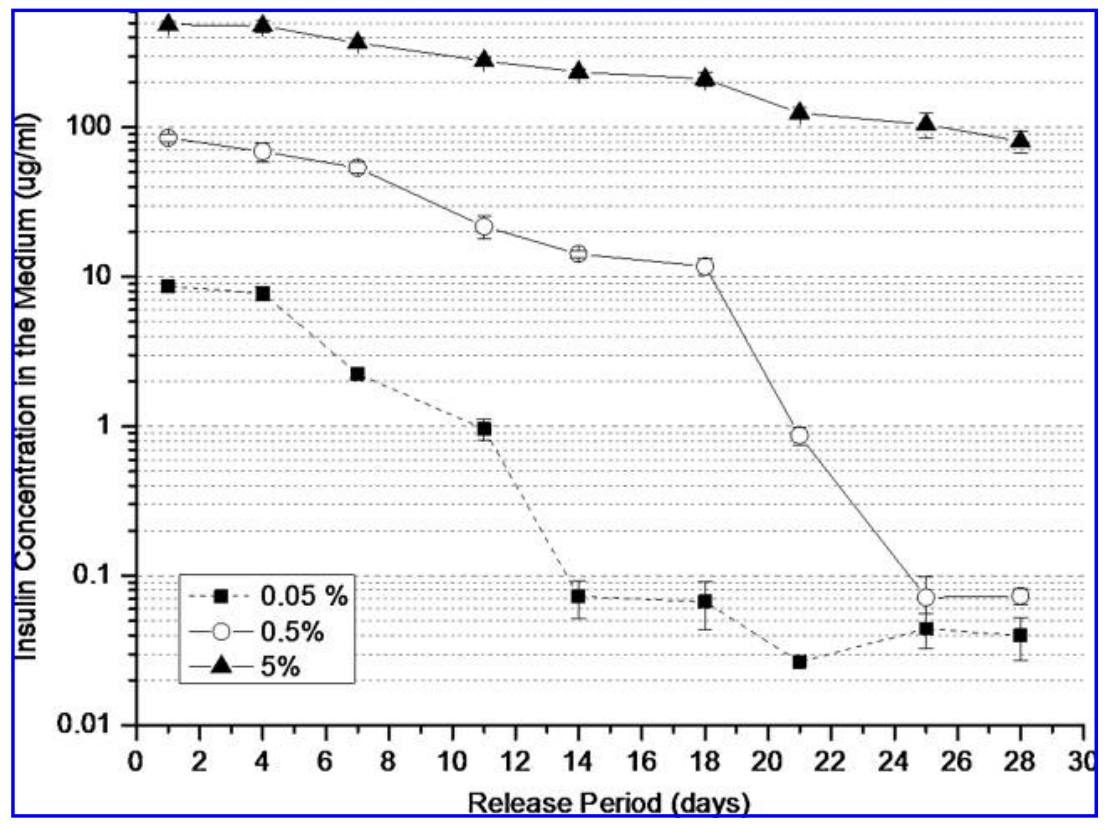



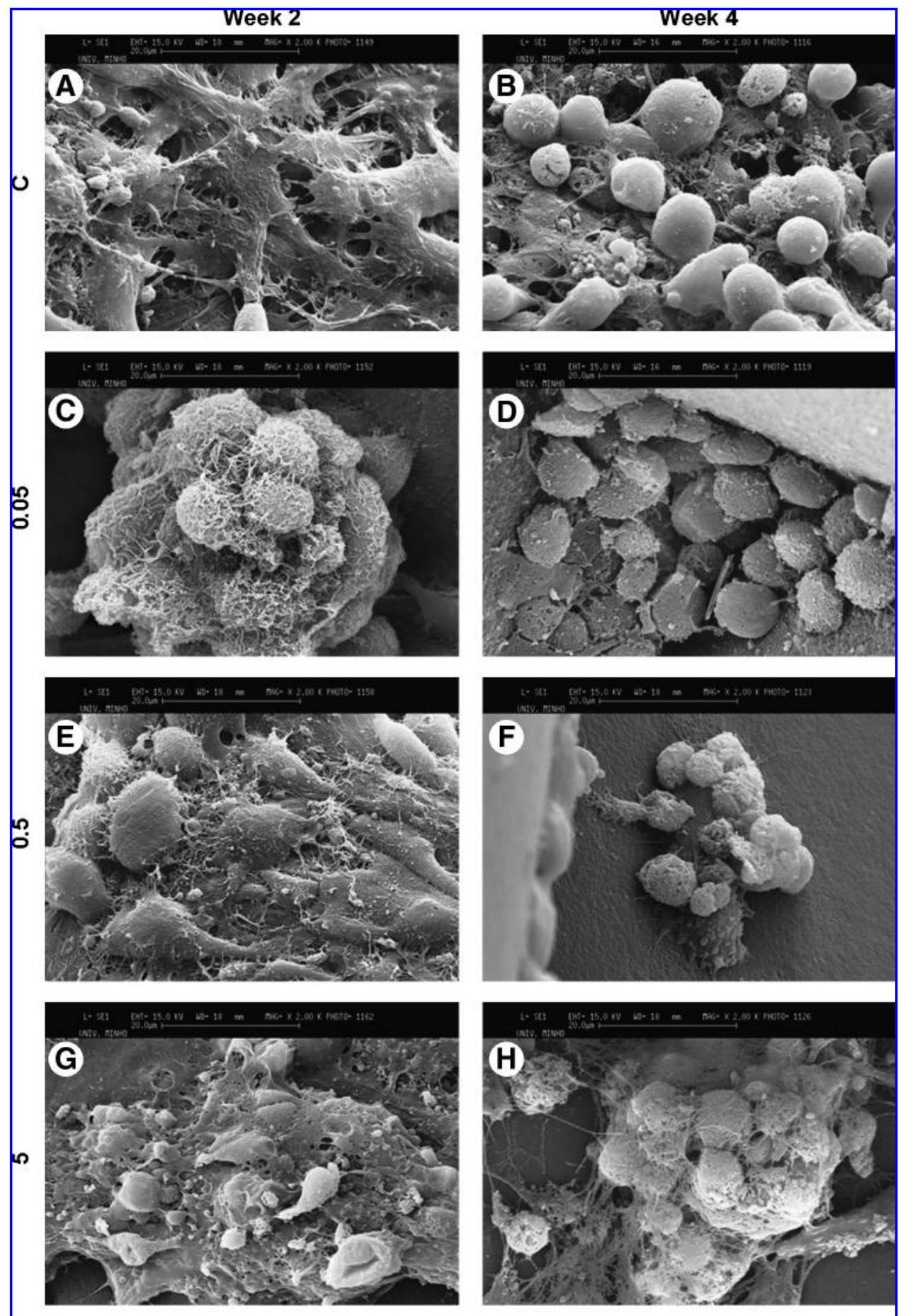

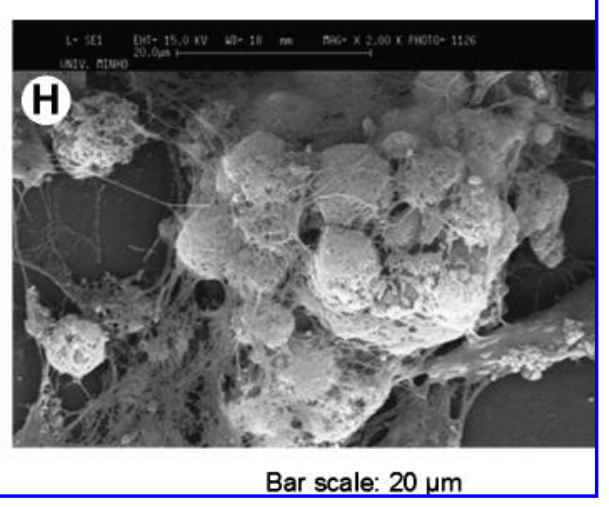

FIG. 4. Scanning electron microscopy microphotographs of chitosan scaffolds loaded with $0 \%(\mathrm{C})(\mathbf{A}, \mathbf{B})$, $0.05 \%(\mathbf{C}, \mathbf{D}), 0.5 \%(\mathrm{E}, \mathbf{F})$, and $5 \%(\mathbf{G}, \mathbf{H})$ of insulin seeded with ATDC5 cells and cultured for 2 weeks (A, C, E, G) and 4 weeks $(\mathbf{B}, \mathbf{D}, \mathbf{F}, \mathbf{H})$. Magnification, 2000×. loaded cell-scaffold constructs, at weeks 2 and 4 (Fig. 6). The GAG content was calculated per DNA content of each formulation. The biochemical analysis demonstrated that the content of GAGs per DNA increased from week 2 to 4 for the higher insulin initial loadings $(0.5 \%$ and $5 \%)$. Comparing the results for 2 weeks of culture, one can say that there is a decreasing tendency with increasing insulin concentrations, in spite of no statistically significant difference found when compared with that of the control. In contrast, for 4 weeks this tendency is inverted with higher GAG contents for higher insulin concentrations. The values of GAG content were $54.22 \pm 5.62 \mu \mathrm{g} / \mu \mathrm{g}$ DNA for control group, $37.08 \pm$ $25.08 \mu \mathrm{g} / \mu \mathrm{g}$ DNA for $0.05 \%, 287.57 \pm 86.04 \mu \mathrm{g} / \mu \mathrm{g}$ DNA for $0.5 \%$, and $188.99 \pm 22.55 \mu \mathrm{g} / \mu \mathrm{g}$ DNA for the $5 \%$ formulation after 4 weeks of culture with ATDC5 cells.

Histological examination. Chondrocytes were seeded onto loaded and unloaded chitosan scaffolds, and the morphologies were observed histologically upon H\&E and toluidine blue staining of sections from the bulk of the scaffolds. Representative sections obtained after 2 and 4 weeks of culture are shown in Figures 7 and 8 for the standard 


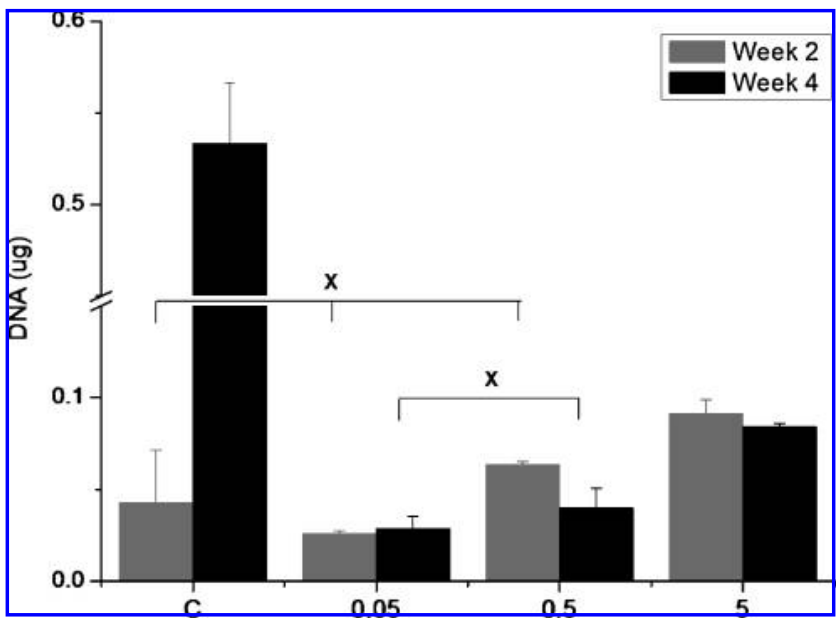

FIG. 5. DNA quantification for chitosan scaffolds (C) loaded with $0.05 \%, 0.5 \%$, and $5 \%$ of insulin cultured with ATDC 5 cells for 2 and 4 weeks. The indicated conditions (x) were found to be not statistically significantly different. Statistically significant difference was found between the other conditions $(p<0.05)$. Scale was adjusted for better observation of tendencies.

condition and higher insulin-loading formulation (5\%). Histological examination of the sections indicated that the chondrocytes were evenly distributed throughout the scaffold and that the chondrocytes were able to infiltrate, adhere, and proliferate into the inner pores of the scaffolds. Analyzing the sections stained with H\&E (Fig. 7), one can say that cells seeded in the insulin-loaded scaffolds have similar morphology compared with the control condition after 2 and 4 weeks. The cell constructs were composed of viable chondrocytes as detected by the H\&E-positive staining. The clustering of chondrocytes was evident after 4 weeks, being more clear for $5 \%$ insulin loading.

Toluidine blue staining showed evidence of viable chondrocytes embedded in a newly synthesized ECM as shown in Figure 8. The histological sections stained mainly metachromatic (purple) indicative of sulfated proteoglycan de-

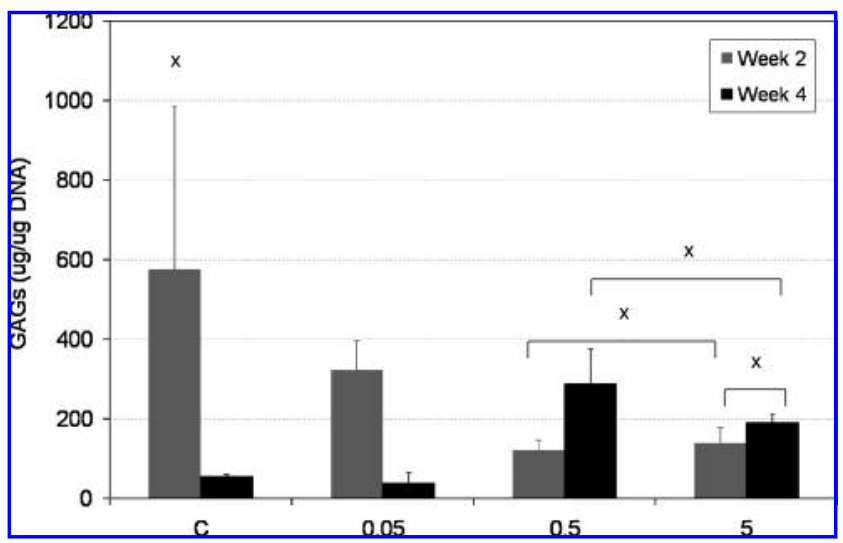

FIG. 6. Glycosaminoglycan (GAG) quantification for chitosan scaffolds (C) loaded with $0.05 \%, 0.5 \%$, and $5 \%$ of insulin cultured with ATDC5 cells for 2 and 4 weeks. The indicated conditions $(x)$ were found to be not statistically significantly different. Statistically significant difference was found between the other conditions $(p<0.05)$. position at 4 weeks of culture. Some orthochromatic areas (blue) were also identified, but these were found primarily at 2 weeks of culture. The central matrix stained positively with toluidine blue, thereby indicating the presence of a cartilaginous matrix composed of proteoglycans. The formation of cell aggregates is once more evident with characteristic lacunae of differentiated chondrocytes that were invested with intense metachromatic matrix as shown in Figure $8 \mathrm{~B}$ and $\mathrm{D}$, suggesting the active deposition of proteoglycan after 4 weeks.

Gene expression. Gene expression of type I collagen, type II collagen, Sox-9, and aggrecan in the loaded constructs after 4 weeks of culture with ATDC5 cells was examined by realtime PCR and normalized for the control condition (ratio $=1$ ). The obtained normalized expression ratios for each gene are shown in Figure 9. The cells in the constructs expressed genes encoding collagen type I, Sox-9, and aggrecan after 4 weeks of culture, except for Sox-9 that was not detected for the $0.05 \%$ insulin-loaded formulation. No expression of collagen type II was identified in any of the groups, including the standard condition. The normalized ratio of Sox-9 gene expression of the insulin-loaded scaffolds with $5 \%$ group significantly increased compared with the standard condition. The same tendency is observed for aggrecan expression, which is also increasing for the higher insulin loading constructs with a 9.6-fold higher ratio. Concerning the values for type I collagen expression, there is no statistically significant difference between the control and the $5 \%$ formulation.

\section{Discussion}

\section{Insulin-chitosan system characterization and in vitro release studies}

Chondrocytes experience biochemical stimulation and mechanical stimulation in vivo that are integral to the development and maintenance of cartilage. Growth factors aid in signaling and regulating cartilage development and ECM maintenance. Growth factors are present in serum and synovial fluid, or may be stored in the cartilage matrix for immediate release when needed. Among these, IGF-1 is considered to be the main anabolic growth factor of normal cartilage. ${ }^{12,16}$ In addition, it is known that insulin has a great structural and functional similarity to IGF-1 and can bind to IGF-1 and insulin receptors with a marked response in cartilage. ${ }^{13,16}$ Further, local delivery of biochemically active substances is ideal, since these proteins often have short halflives and multiple biological effects with potential systemic toxicity. Investigation of novel experimental application systems for growth factors or other bioactive substances in tissue engineering is often limited by high costs of substances and would benefit from a defined and easily controllable model system, namely, using insulin as a differentiation biomolecule since it is a readily available protein. In addition, release technology approaches can further improve the function of active biomolecules, namely, in an in vivo situation where a single-dose application cannot guarantee a prolonged local protein concentration. Further, when aiming at osteochondral applications, systems loaded with different adequate differentiation agents can be assembled in a biphasic construct, allowing for selective but simultaneous 

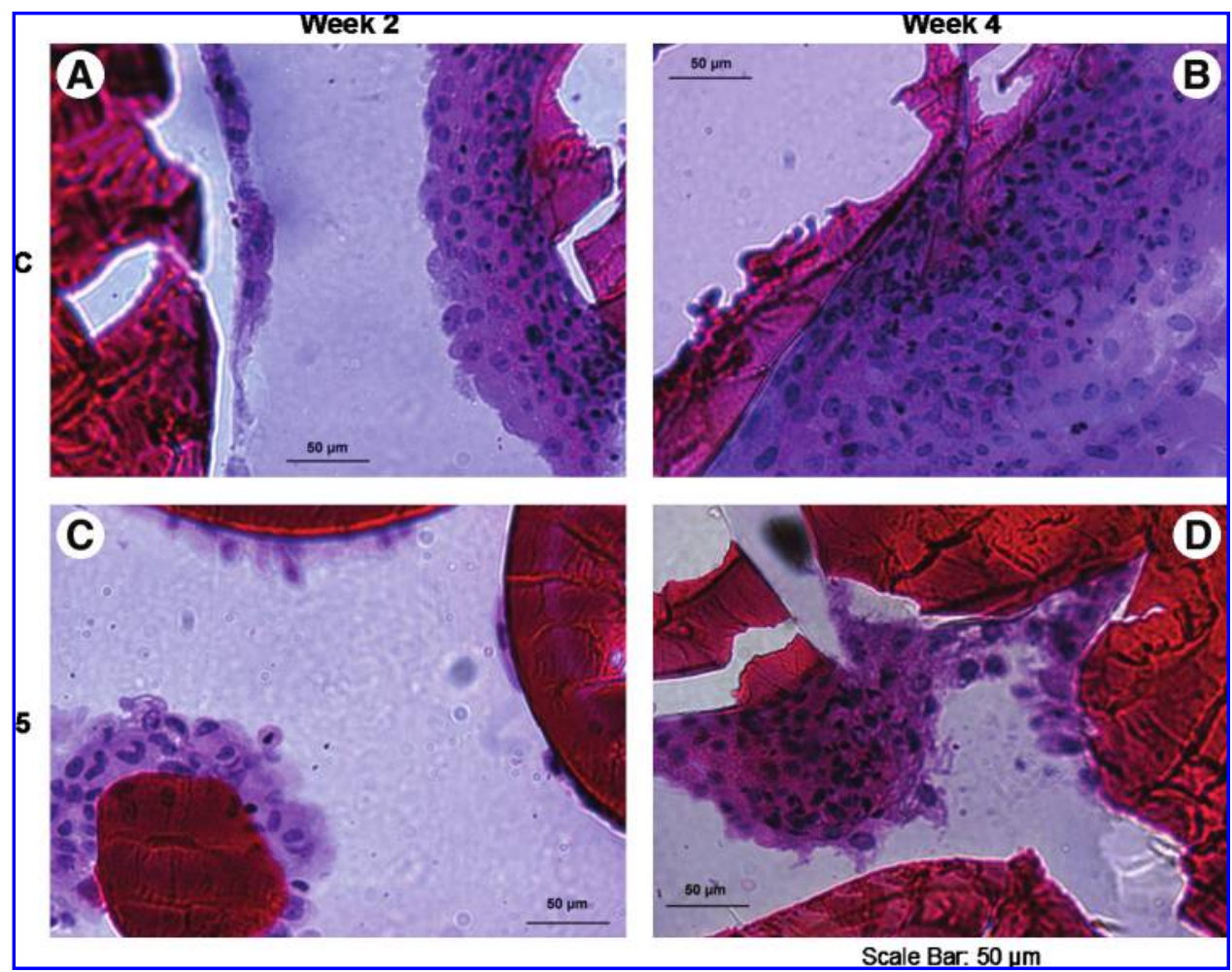

FIG. 7. Representative histological sections stained with hematoxylin-eosin of chitosan-based scaffolds (A, B) and chitosan-based scaffolds loaded with $5 \%$ insulin $(\mathbf{C}, \mathbf{D})$ after $2(\mathbf{A}, \mathbf{C})$ and 4 weeks (B, D) of culture with ATDC5 cells. Magnification, $400 \times$. Color images available online at www.liebertonline .com/ten. differentiation of a single source of stem cells into both chondrogenic and osteogenic pathways.

Having this in mind, we aimed in this work to incorporate insulin in a chitosan particle-aggregated scaffold to aid in cartilage tissue engineering. The future final goal will involve the incorporation of these insulin systems in osteochondral biphasic constructs to selectively but simultaneously differentiate the same cell source into the chondrogenic and osteogenic lineages. For that purpose, insulin was successfully incorporated at different concentrations in chitosan matrices as shown by the obtained high encapsulation efficiencies and protein loadings.
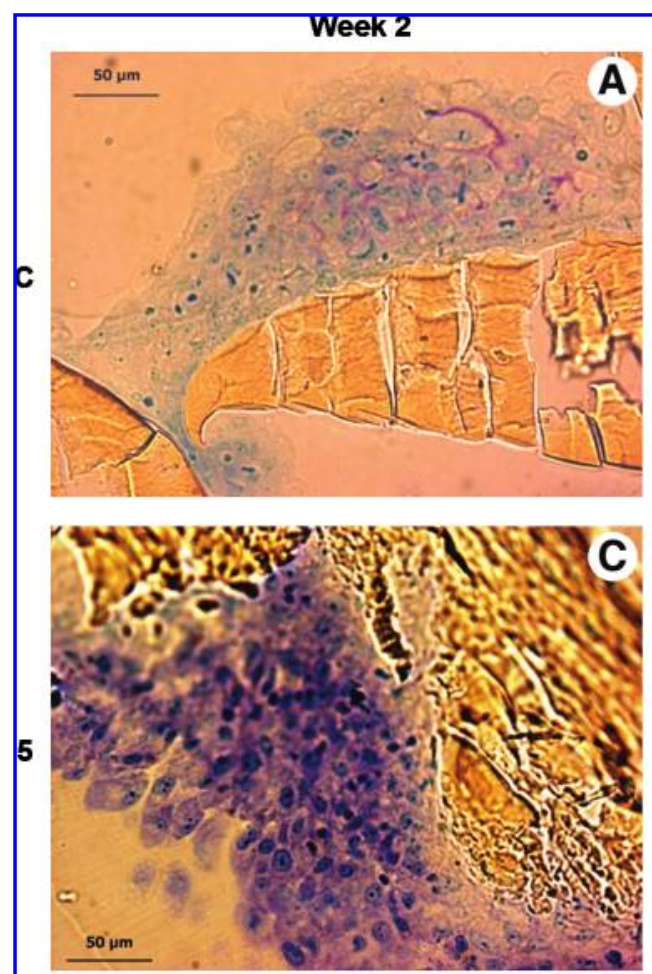
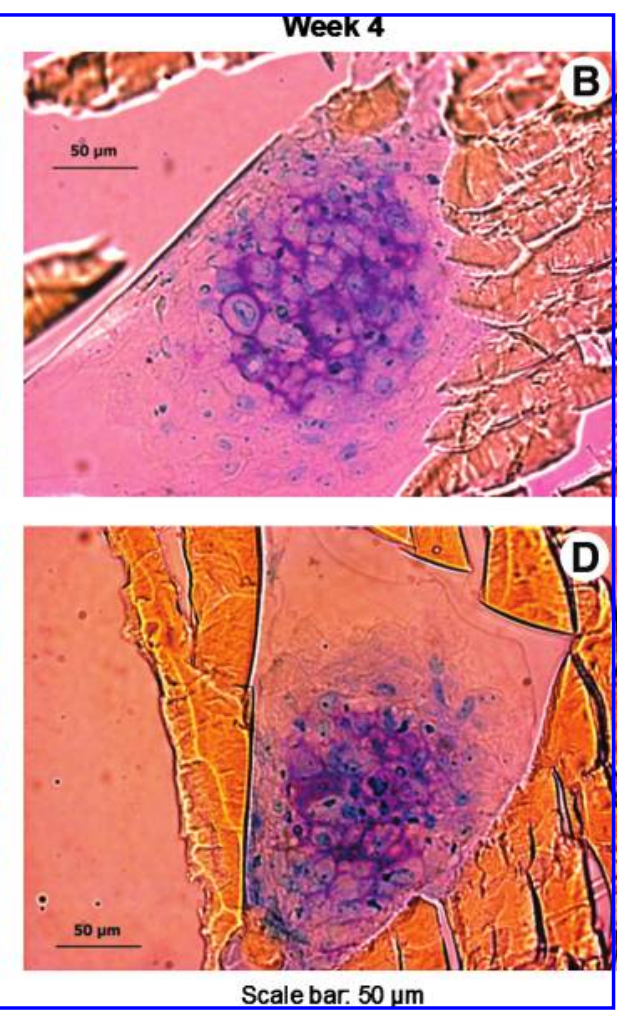

FIG. 8. Representative histological sections stained with toluidine blue of chitosanbased scaffolds (A, B) and chitosan-based scaffolds loaded with 5\% insulin (C, D) after $2(\mathbf{A}, \mathbf{C})$ and 4 weeks $(\mathbf{B}$, D) of culture with ATDC5 cells. Magnification, $400 \times$. Color images available online at www.liebertonline .com/ten. 


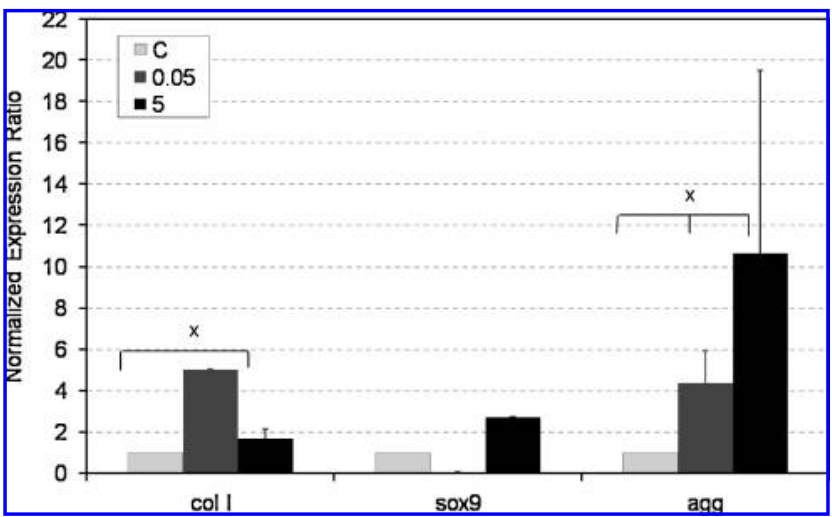

FIG. 9. Normalized gene expression ratio of collagen type I (col I), Sox-9 (sox9), and aggrecan (agg) assessed by real-time polymerase chain reaction of chitosan-based scaffolds loaded with $0 \%(\mathrm{C}), 0.05 \%$, and $5 \%$ of insulin cultured with ATDC5 cells for a 4-week period. The ratios were normalized relative to the control (ratio $=1$, nonloaded scaffolds cultured with the chondrogenic medium). The indicated conditions (x) were not statistically significantly different. Statistically significant difference was found between the other conditions $(p<0.05)$.

It is known that chitosan is positively charged due to the protonation of the amino groups, and insulin is negatively charged at $\mathrm{pH}$ above its isoelectric point. Consequently, electrostatic interactions between both materials can be used as a driving force for insulin incorporation into chitosan matrices. ${ }^{34}$ This is one key issue that explains why chitosan has been widely investigated as carrier for insulin delivery for other than tissue engineering applications, such as oral insulin delivery ${ }^{35,36}$ or self-assembled polyelectrolyte nanocomplexes for intranasal absorption ${ }^{34}$ or oral delivery. ${ }^{37}$ The obtained real protein loading values correlated well with the intended insulin theoretical loadings, in spite of the slight insulin loss that can be attributed to the washing procedure required for the particle-aggregated scaffold production. In the same way, the encapsulation efficiencies were also high. These values shown to be dependent on the insulin content, increasing for higher initial insulin concentrations in the scaffolds. The same dependence was observed for the release profiles that correlated well in terms of order of magnitude with the initial insulin loading. For lower initial insulin contents, there was a burst release on the first days of immersion. Nevertheless, insulin levels in the release medium were above $1 \mu \mathrm{g} / \mathrm{mL}$ until day 11 for $0.05 \%$ formulation and day 21 for $0.5 \%$. This burst effect was less evident for the higher insulin-loaded scaffolds that, in general, presented best performance in the biological tests. For the higher initial loading, insulin concentration in the medium was above $80 \mu \mathrm{g} / \mathrm{mL}$ until the end of the experiment. The insulin monomer contains many ionizable groups, due to 6 amino acid residues capable of attaining a positive charge and 10 amino acid residues capable of attaching a negative charge. ${ }^{38}$ These properties are, therefore, possibly responsible for the entrapment of insulin into chitosan matrices due to the electrostatic interaction between the protein and the polyanion that might also favor the retention of insulin within the chitosan matrix. ${ }^{39}$

\section{Biological assessment of ATDC5 chondrogenic differentiation by insulin-loaded scaffolds}

Cell morphology. There are several studies ${ }^{7,19}$ reporting the use of insulin for cartilage tissue engineering. The most typical approach is obviously the use of insulin as a differentiating agent in the cell culture medium, and it is used nowadays as a standard condition in the chondrogenic differentiation medium. The group of Gopferich ${ }^{19,40,41}$ has been working in different strategies, including this standard approach, ${ }^{19}$ but also going from the incorporation of insulinloaded microspheres into fibrin hydrogels with encapsulated chondrocytes ${ }^{41}$ to the development of lipidic cylinders that are placed together with the seeded scaffolds for insulincontrolled release. ${ }^{40}$ The reported studies show in a general way that insulin is able to promote cartilage formation by improving the quality of the cartilaginous constructs, since it increases the collagen content and promotes GAG deposition. ${ }^{40,41}$ Nevertheless, to the best of our knowledge, this is the first study with direct insulin encapsulation into tissue engineering scaffolds.

In this study, the bioactivity of the released insulin as well as its influence on chondrogenic differentiation was studied with long-term culture of ATDC5 cells for a period up to 28 days. ATDC5 cells are an example of a prechondrogenic stem cell line and reproduce the differentiation stages of chondrocytes. ${ }^{10}$ In monolayer culture and only in presence of insulin (or other chondrogenic differentiation agent), ATDC5 cells retain the properties of chondroprogenitor cells that are at the early phase of differentiation and form cartilage nodules when cells reach condensation. ${ }^{18}$ The cartilage nodules enlarge while chondrocytes proliferate, for about 2 weeks in culture. The ATDC5 cell line is the first example to display the entire spectrum of chondrocyte differentiation. ${ }^{10}$ Our results showed that ATDC5 cells were able to attach and were dispersed throughout the scaffolds after 2 weeks of culture. Cellular condensation was observed for the insulin-loaded scaffolds, which is one of the key events in chondrogenesis. ${ }^{42}$ The capability of chondrocytes to synthesize and retain their matrix in close cell proximity is the basis of the chondrocyte phenotype and is vitally important in maintaining their rounded cell shape. ${ }^{3}$ After 2 weeks of culture in the insulinloaded scaffolds, the majority of cells presented a rounded morphology, whereas in the control condition some flattened elongated cells could be detected. After 4 weeks of culture, the cells were already with the typical round chondrocytic morphology in all the studied groups. The deposition of newly formed ECM was possible to be observed microscopically, and collagen fibrils were also detected. ${ }^{33}$

Cell proliferation. Concerning cell proliferation after 2 weeks, the highest concentration insulin (5\%) showed to have a positive effect on DNA content. This effect was inverted for longer culture periods, which can be considered as an indication of cell differentiation events. It is well known that generally cell differentiation goes along with a reduction of cell proliferation, since chondrogenesis results from a complex equilibrium between chondrocyte proliferation and differentiation. ${ }^{43}$ This may also be related with the higher concentration of insulin present in the medium. In the standard condition, cell-scaffold constructs are exposed to $10 \mu \mathrm{g} / \mathrm{mL}$ of insulin, whereas in the higher concentration 
of insulin-loaded scaffolds (5\%), the concentration is always above $80 \mu \mathrm{g} / \mathrm{mL}$. It is known that insulin is a potent differentiating agent, but not a potent mitogen for chondrocytes, ${ }^{13}$ and this higher concentration may be inhibiting its proliferative capacity.

GAG quantification. The biochemical analysis demonstrated that the content of GAGs increased from week 2 to 4 for higher insulin-loading scaffolds, indicating that typical ECM components were being deposited occur biosynthesis, thereby confirming the differentiation of the ATDC5 cells toward the chondrogenic lineage. The GAGs production is higher for control condition at 2 weeks and $0.5 \%$ at 4 weeks compared with the $5 \%$ formulation, due to the lower DNA content at the respective time periods. On the other hand, in the control condition, GAG content decreased substantially from 2 to 4 weeks of culture due to the substantial increase in cell proliferation in unloaded scaffolds.

Histological examination. Histologically, it was also possible to observe that the chondrocytes were able to infiltrate, adhere, and proliferate into the inner pores of the scaffolds. This reflects the advantageous structural design of these scaffolds that present a high interconnectivity degree as characterized in previous works. ${ }^{44,45}$ Further, toluidine blue staining demonstrated the typical metachromasia of the articular cartilage matrix both to the control condition and $5 \%$ insulin-loaded scaffolds after 4 weeks of culture. Toluidine blue dyes form complexes with anionic glycoconjugates such as proteoglycans and GAGs, and its positive staining is therefore an evidence of proteoglycan deposition for ECM production. ${ }^{46}$ Further, the observed morphology is consistent to that observed with mature chondrocytes, which are predominantly round cells located in matrix cavities called lacunae. ${ }^{10}$

Gene expression. The results of the real-time PCR confirmed the mRNA expression of genes encoding the specific ECM markers for cartilaginous tissue, such as Sox-9 and aggrecan. The transcription factor Sox-9 is considered to be a crucial factor in chondrocyte differentiation and cartilage formation and is required to maintain the chondrocytes phenotype. ${ }^{10}$ Aggrecan is a large chondroitin sulfate proteoglycan and one of the main macromolecules constituting the cartilaginous ECM, which is responsible for the tissues compressive resistance. ${ }^{10}$ The cells seeded in high insulin content scaffolds revealed higher expression of these genes, suggesting the development of phenotypic characteristics consistent with chondrocytes. The insulin-loaded scaffolds with $5 \%$ showed a 1.7 -fold change significantly higher upregulation for Sox-9 and 9.6-fold higher for aggrecan when compared with the standard condition after 4 weeks of culture. Sox-9 is known to promote chondrocyte differentiation in part by activating chondrocyte-specific enhancer elements in aggrecan. ${ }^{47}$ This finding is supported by our results, which showed that insulin-loaded scaffolds induced an increase in Sox-9 in association with a substantial upregulation of aggrecan mRNA. However, Sox-9 is also known to regulate the expression of collagen type II. ${ }^{10,47}$ In this study, no expression of collagen type II was detected for any group. This is probably related to the fact that in this preliminary study a cell line was used given the high number of complementary analyses needed to obtain conclusive results. It is expected that the expression of collagen type II would increase significantly when using primary cells. However, it is known that chondrocytes can dedifferentiate with change in shape, production of collagen type I, and changes in the metabolic pattern of their proteoglycan synthesis. ${ }^{33,43}$ In the present paper, the typical round chondrocytic morphology was maintained after 4 weeks for all the studies groups. Further, for higher insulin content, the proteoglycan synthesis was increasing as detected by toluidine blue, and GAG quantification and the gene expression of Sox-9 and aggrecan were also higher. Moreover, no significant upregulation in collagen type I was measured. Further studies would be necessary with primary cells to overcome the absence of expression of collagen type II expression in all the studied groups.

Cell culture and tissue culture systems have long been known to display insulinase activity, which can rapidly and markedly reduce the effective insulin concentration. ${ }^{13}$ This is particularly relevant to the studies in which the long-term effects on ATDC5 cell differentiation are investigated, such as the one describe herein. This is a possible explanation why, from the overall results, the higher insulin concentration was more effective on promoting chondrogenic differentiation. Nevertheless, there are studies that report that the insulin receptor can initiate and sustain a differentiation promoting signal in chondrocytes, ${ }^{13}$ explaining the slight biochemical effects of lower insulin content formulations $(0.05 \%$ and $0.5 \%)$ after 4 weeks, even though the release was complete.

As an overall remark, one can mention that the most promising results were obtained with ATDC 5 cells seeded in the higher insulin-loaded scaffolds (5\%) that showed a typical chondrocytic round morphology with visible cell condensation. Cells were positively stained by toluidine blue, presented a high GAGs production, and expressed genes encoding cartilaginous markers such as Sox-9 and aggrecan, which suggest the formation of cartilaginous tissue. Further, in the developed insulin-release systems, the insulin retained its bioactivity for at least 28 days, which is in agreement with other reported studies. ${ }^{40,48}$

\section{Conclusions}

This work reports the possibility to incorporate insulin as a potent substance for cartilage tissue engineering in a chitosan particle-aggregated scaffold. It is an easily controllable in vitro release system using insulin as a model protein, since its potent differentiating capacity in chondrocytes is well known. In addition, this approach opens the possibility to assemble the developed systems in bilayered constructs to promote selective differentiation of cartilage and bone in osteochondral applications. The results showed high encapsulation efficiencies, well correlated protein loadings, and adequate release profiles. The chondro-inductive effect of the insulin-loaded scaffolds was further investigated with longterm ATDC5 cell culture. The cells seeded in the higher insulin-loaded scaffolds $(5 \%)$ showed a round morphology and were able to synthesize GAGs. ATDC5 stained positively for proteoglycans and evidenced an upregulation of the expression profiles of cartilaginous genes Sox-9 and aggrecan when compared with the standard condition. Therefore, the 
results of this study demonstrate the ability of insulin-loaded chitosan scaffolds to support chondrocyte attachment and differentiation, as well as cartilaginous matrix biosynthesis in a dose-dependent manner, opening interesting prospects for their use in therapeutical approaches to treat osteochondral lesions.

\section{Acknowledgments}

The authors would like to acknowledge the Portuguese Foundation for Science and Technology for the Ph.D. Grant to Patrícia B. Malafaya (SFRH/BD/11155/2002). This work was partially supported and carried out under the scope of the European STREP Project HIPPOCRATES (NMP3-CT2003-505758) and European NoE EXPERTISSUES (NMP3CT-2004-500283). The authors also like to acknowledge the Life and Health Sciences Research Institute (ICVS), University of Minho, for the use of their facilities, namely, to Luís Martins for histological sections slicing and H\&E stain processing.

\section{Disclosure Statement}

No competing financial interests exist.

\section{References}

1. Martin, I., Miot, S., Barbero, A., Jakob, M., and Wendt, D. Osteochondral tissue engineering. J Biomech 40, 750, 2007.

2. Mano, J.F., and Reis, R.L. Osteochondral defects: present situation and tissue engineering approaches. J Tissue Eng Regen Med 1, 261, 2007.

3. Chaipinyo, K., Oakes, B.W., and van Damme, M.P. Effects of growth factors on cell proliferation and matrix synthesis of low-density, primary bovine chondrocytes cultured in collagen I gels. J Orthop Res 20, 1070, 2002.

4. Cucchiarini, M., Sohier, J., Mitosch, K., Kaul, G., Zurakowski, D., Bezemer, J.M., Kohn, D., and Madry, H. Effect of transforming growth factor-beta 1 (TGF-B1) released from a scaffold on chondrogenesis in an osteochondral defect model in the rabbit. Cent Eur J Biol 1, 43, 2006.

5. Elisseeff, J., McIntosh, W., Fu, K., Blunk, B.T., and Langer, R. Controlled-release of IGF-I and TGF-beta1 in a photopolymerizing hydrogel for cartilage tissue engineering. J Orthop Res 19, 1098, 2001.

6. Fukumoto, T., Sperling, J.W., Sanyal, A., Fitzsimmons, J.S., Reinholz, G.G., Conover, C.A., and O'Driscoll, S.W. Combined effects of insulin-like growth factor-1 and transforming growth factor-beta1 on periosteal mesenchymal cells during chondrogenesis in vitro. Osteoarthritis Cartilage 11, 55, 2003.

7. Martin, I., Shastri, V.P., Padera, R.F., Yang, J., Mackay, A.J., Langer, R., Vunjak-Novakovic, G., and Freed, L.E. Selective differentiation of mammalian bone marrow stromal cells cultured on three-dimensional polymer foams. J Biomed Mater Res 55, 229, 2001.

8. Swieszkowski, W., Tuan, B.H.S., Kurzydlowski, K.J., and Hutmacher, D.W. Repair and regeneration of osteochondral defects in the articular joints. Biomol Eng 24, 489, 2007.

9. Frenkel, S.R., Bradica, G., Brekke, J.H., Goldman, S.M., Ieska, K., Issack, P., Bong, M.R., Tian, H., Gokhale, J., Coutts, R.D., and Kronengold, R.T. Regeneration of articular cartilageevaluation of osteochondral defect repair in the rabbit using multiphasic implants. Osteoarthritis Cartilage 13, 798, 2005.

10. Lin, Z., Willers, C., Xu, J., and Zheng, M.-H. The chondrocyte: biology and clinical application. Tissue Eng 12, 1971, 2006.
11. Bohme, K., Conscience-Egli, M., Tschan, T., Winterhalter, K.H., and Bruckner, P. Induction of proliferation or hypertrophy of chondrocytes in serum-free culture: the role of insulin-like growth factor-I, insulin, or thyroxine. J Cell Biol 116, 1035, 1992.

12. van der Kraan, P.M., Buma, P., van Kuppevelt, T., and van den Berg, W.B. Interaction of chondrocytes, extracellular matrix and growth factors: relevance for articular cartilage tissue engineering. Osteoarthritis Cartilage 10, 631, 2002.

13. Phornphutkul, C., Wu, K.-Y., and Gruppuso, P.A. The role of insulin in chondrogenesis. Mol Cell Endocrinol 249, 107, 2006.

14. Phornphutkul, C., Wu, K.Y., Yang, X., Chen, Q., and Gruppuso, P.A. Insulin-like growth factor-I signaling is modified during chondrocyte differentiation. I Endocrinol 183, 477, 2004.

15. Madry, H., Kaul, G., Cucchiarini, M., Stein, U., Zurakowski, D., Remberger, K., Menger, M.D., Kohn, D., and Trippel, S.B. Enhanced repair of articular cartilage defects in vivo by transplanted chondrocytes overexpressing insulin-like growth factor I (IGF-I). Gene Ther 12, 1171, 2005.

16. Schmid, C. Insulin-like growth factors. Cell Biol Int 19, 445, 1995.

17. Darling, E.M., and Athanasiou, K.A. Growth factor impact on articular cartilage subpopulations. Cell Tissue Res 322, 463, 2005.

18. Shukunami, C., Shigeno, C., Atsumi, T., Ishizeki, K., Suzuki, F., and Hiraki, Y. Chondrogenic differentiation of clonal mouse embryonic cell line ATDC5 in vitro: differentiationdependent gene expression of parathyroid hormone (PTH)/ PTH-related peptide receptor. J Cell Biol 133, 457, 1996.

19. Kellner, K., Schulz, M.B., Gopferich, A., and Blunk, T. Insulin in tissue engineering of cartilage: a potential model system for growth factor application. J Drug Target 9, 439, 2001.

20. Gotterbarm, T., Richter, W., Jung, M., Berardi Vilei, S., Mainil-Varlet, P., Yamashita, T., and Breusch, S.J. An in vivo study of a growth-factor enhanced, cell free, two-layered collagen-tricalcium phosphate in deep osteochondral defects. Biomaterials 27, 3387, 2006.

21. Holland, T.A., Bodde, E.W.H., Cuijpers, V.M.J.I., Baggett, L.S., Tabata, Y., Mikos, A.G., and Jansen, J.A. Degradable hydrogel scaffolds for in vivo delivery of single and dual growth factors in cartilage repair. Osteoarthritis Cartilage 15, 187, 2007.

22. Mierisch, C.M., Cohen, S.B., Jordan, L.C., Robertson, P.G., Balian, G., and Diduch, D.R. Transforming growth factorbeta in calcium alginate beads for the treatment of articular cartilage defects in the rabbit. Arthroscopy 18, 892, 2002.

23. Tuzlakoglu, K., Bolgen, N., Salgado, A.J., Gomes, M.E., Piskin, E., and Reis, R.L. Nano- and micro-fiber combined scaffolds: a new architecture for bone tissue engineering. J Mater Sci Mater Med 16, 1099, 2005.

24. Gomes, M.E., Bossano, C.M., Johnston, C.M., Reis, R.L., and Mikos, A.G. In vitro localization of bone growth factors in constructs of biodegradable scaffolds seeded with marrow stromal cells and cultured in a flow perfusion bioreactor. Tissue Eng 12, 177, 2006.

25. Marques, A.P., Reis, R.L., and Hunt, J.A. An in vivo study of the host response to starch-based polymers and composites subcutaneously implanted in rats. Macromol Biosci 5, 775, 2005.

26. Malafaya, P.B., Pedro, A., Peterbauer, A., Gabriel, C., Redl, H., and Reis, R.L. Chitosan particles agglomerated scaffolds for cartilage and osteochondral tissue engineering appro- 
aches with adipose tissue derived stem cells. J Mater Sci Mater Med 16, 1077, 2005.

27. Kim, I.Y., Seo, S.J., Moon, H.S., Yoo, M.K., Park, I.Y., Kim, B.C., and Cho, C.S. Chitosan and its derivatives for tissue engineering applications. Biotechnol Adv 26, 1, 2008.

28. Cai, D.Z., Zeng, C., Quan, D.P., Bu, L.S., Wang, K., Lu, H.D., and Li, X.F. Biodegradable chitosan scaffolds containing microspheres as carriers for controlled transforming growth factor-beta1 delivery for cartilage tissue engineering. Chin Med J (Engl) 120, 197, 2007.

29. Kim, S.E., Park, J.H., Cho, Y.W., Chung, H., Jeong, S.Y., Lee, E.B., and Kwon, I.C. Porous chitosan scaffold containing microspheres loaded with transforming growth factor-beta1: implications for cartilage tissue engineering. J Controlled Release 91, 365, 2003.

30. Lee, J.E., Kim, K.E., Kwon, I.C., Ahn, H.J., Lee, S.H., Cho, H., Kim, H.J., Seong, S.C., and Lee, M.C. Effects of the controlled-released TGF-beta1 from chitosan microspheres on chondrocytes cultured in a collagen/chitosan/ glycosaminoglycan scaffold. Biomaterials 25, 4163, 2004.

31. Jong, E.L., Seoung, E.K., Ick, C.K., Hyun, J.A., Cho, H., Lee, S.H., Hee, J.K., Sang, C.S., and Myung, C.L. Effects of a chitosan scaffold containing TGF-beta1 encapsulated chitosan microspheres on in vitro chondrocyte culture. Artif Organs 28, 829, 2004.

32. Uchihashi, T., Kimata, M., Tachikawa, K., Koshimizu, T., Okada, T., Ihara-Watanabe, M., Sakai, N., Kogo, M., Ozono, K., and Michigami, T. Involvement of nuclear factor I transcription/replication factor in the early stage of chondrocytic differentiation. Bone 41, 1025, 2007.

33. Kino-Oka, M., Yashiki, S., Ota, Y., Mushiaki, Y., Sugawara, K., Yamamoto, T., Takezawa, T., and Taya, M. Subculture of chondrocytes on a collagen type I-coated substrate with suppressed cellular dedifferentiation. Tissue Eng 11, 597, 2005.

34. Mao, S., Bakowsky, U., Jintapattanakit, A., and Kissel, T. Self-assembled polyelectrolyte nanocomplexes between chitosan derivatives and insulin. J Pharm Sci 95, 1035, 2006.

35. Ubaidulla, U., Sultana, Y., Ahmed, F.J., Khar, R.K., and Panda, A.K. Chitosan phthalate microspheres for oral delivery of insulin: preparation, characterization, and in vitro evaluation. Drug Deliv 14, 19, 2007.

36. Sajeesh, S., and Sharma, C.P. Interpolymer complex microparticles based on polymethacrylic acid-chitosan for oral insulin delivery. J Appl Polym Sci 99, 506, 2006.

37. Sarmento, B., Martins, S., Ribeiro, A., Veiga, F., Neufeld, R., and Ferreira, D. Development and comparison of different nanoparticulate polyelectrolyte complexes as insulin carriers. Int J Pept Res Ther 12, 131, 2006.

38. Wang, L.Y., Gu, Y.H., Su, Z.G., and Ma, G.H. Preparation and improvement of release behavior of chitosan microspheres containing insulin. Int J Pharm 311, 187, 2006.

39. Boonsongrit, Y., Mitrevej, A., and Mueller, B.W. Chitosan drug binding by ionic interaction. Eur J Pharm Biopharm 62, 267, 2006.

40. Appel, B., Maschke, A., Weiser, B., Sarhan, H., Englert, C., Angele, P., Blunk, T., and Gopferich, A. Lipidic implants for controlled release of bioactive insulin: effects on cartilage engineered in vitro. Int J Pharm 314, 170, 2006.
41. Maschke, A., Becker, C., Eyrich, D., Kiermaier, J., Blunk, T., and Gopferich, A. Development of a spray congealing process for the preparation of insulin-loaded lipid microparticles and characterization thereof. Eur J Pharm Biopharm 65, $175,2007$.

42. Fujita, T., Fukuyama, R., Enomoto, H., and Komori, T. Dexamethasone inhibits insulin-induced chondrogenesis of ATDC5 cells by preventing PI3K-Akt signaling and DNA binding of Runx2. J Cell Biochem 93, 374, 2004.

43. Spagnoli, A., Hwa, V., Horton, W.A., Lunstrum, G.P., Roberts, C.T., Jr., Chiarelli, F., Torello, M., and Rosenfeld, R.G. Antiproliferative effects of insulin-like growth factorbinding protein-3 in mesenchymal chondrogenic cell line RCJ3.1C5.18. Relationship to differentiation stage. J Biol Chem 276, 5533, 2001.

44. Malafaya, P.B., Santos, T.C., Griensven, M.v., and Reis, R.L. Morphometric, mechanical characterization and in vivo neovascularization of novel chitosan particle aggregated tissue engineering scaffolding architectures. Biomaterials 29, 3914, 2008.

45. Malafaya, P.B., and Reis, R.L. Bilayered chitosan-based scaffolds for osteochondral tissue engineering: influence of hydroxylapatite on in-vitro cytotoxicity and dynamic bioactivity studies in a specific double chamber bioreactor. Acta Biomater 5, 644, 2009.

46. Wenger, R., Hans, M.G., Welter, J.F., Solchaga, L.A., Sheu, Y.R., and Malemud, C.J. Hydrostatic pressure increases apoptosis in cartilage-constructs produced from human osteoarthritic chondrocytes. Front Biosci 11, 1690, 2006.

47. Robins, J.C., Akeno, N., Mukherjee, A., Dalal, R.R., Aronow, B.J., Koopman, P., and Clemens, T.L. Hypoxia induces chondrocyte-specific gene expression in mesenchymal cells in association with transcriptional activation of Sox9. Bone 37, 313, 2005.

48. Ibrahim, M.A., Ismail, A., Fetouh, M.I., and Gopferich, A. Stability of insulin during the erosion of poly(lactic acid) and poly(lactic-co-glycolic acid) microspheres. J Control Release 106, 241, 2005.

Address correspondence to:

Patrícia B. Malafaya, Ph.D.

3B's Research Group, Biomaterials

Biodegradables, and Biomimetics

Department of Polymer Engineering

University of Minho

Headquarters of the European Institute of Excellence on Tissue Engineering and Regenerative Medicine

AvePark, Zona Industrial da Gandra

S. Cláudio do Barco

4806-909 Caldas das Taipas

Guimarães

Portugal

E-mail: pmalafaya@dep.uminho.pt

Received: December 16, 2008

Accepted: September 21, 2009

Online Publication Date: November 19, 2009 
